\title{
SIMULATION PROJECT FOR LOGISTICS OF BRAZILIAN SOYBEAN EXPORTATION
}

\author{
Lopes, H. S. ; Lima, R. S. ${ }^{* *} \&$ Leal, F.** \\ * Industrial Engineering Faculty, Federal University of Pará, Manoel de Abreu s/n, \\ 68440-000 Abaetetuba, PA, Brazil \\ ${ }^{* *}$ Institute of Production Engineering and Management, Federal University of Itajubá, \\ 1303 BPS Avenue PO Box: 50, 37500-903 Itajubá, MG, Brazil \\ E-Mail: harlenn@ufpa.br; rslima@unifei.edu.br; fleal@unifei.edu.br
}

\begin{abstract}
Decision-making in complex logistics systems involves high risks and associated impacts. A way to forecast the impacts of these decisions is through the use of systems simulation projects, where the systematic impacts of the parameters can be visualized. This study presents a project based on DiscreteEvent Simulation (DES) that analyses Brazilian soybean export logistics from producing regions to main international customers. The strategic analysis of a global logistics system using DES is a particularity of this study. At the conception stage, the conceptual modelling was made using IDEF-SIM (Integrated Definition Methods - Simulation) method, which allowed a better abstraction of reality and more accurate model implementation. The experimental analysis took place through the construction of 39 scenarios with specific characteristics that verified system behaviours through proposed changes. The analyses and decisions are based on costs. The simulations indicated the necessity for: a) an integrated management between the systems agents; b) the development of internal transportation infrastructure, especially railways and waterways, to increase competitiveness of Brazilian soybeans in the international market.
\end{abstract}

(Received in July 2020, accepted in October 2020. This paper was with the authors 2 weeks for 3 revisions.)

Key Words: Simulation Project, Discrete-Event Simulation, Conceptual Modelling, Logistics, Soybean

\section{INTRODUCTION}

In recent years, few countries have grown as much as Brazil in international agribusiness. The country is now a world leader in the production and export of various agricultural products [1]. However, Brazil has a visible bottleneck for exportation of agricultural products stemming directly related to logistics [2]. Road improvements, greater use of railways and waterways, aside from enhancements of their ports and storage centres are all greatly needed [2,3]. For the production regions located the farthest from exporting ports, transportation costs represent around $27 \%$ of the price of soybeans which arrive at the importing port; of this, $20 \%$ is related to 'internal' transportation within the country's borders [4]. This set of interrelated variables requires studies to support integrated strategic decisions, involving high risks, associated impacts and unintended consequences.

Private companies, producers and exporters of Brazilian soybeans carry out their logistical management individually or through joint ventures, planning and structuring the logistical chain in an autonomous and individualized manner, with limited integration and little or no participation from the public sector [1].

There has been a growth in studies that seek solutions for Brazilian soybean logistics [1-3, 5-7]. However, much of the recent research is either empirical or qualitative [2, 6, 7]. The quantitative works, on the other hand, mostly use static, optimization models [3], with reduced numbers of variables or with specific problem solving $[3,6]$, related to a route, axis or determined transport system $[1,5]$; they typically do not model the integration of a high number of variables, nor do they consider the dynamism of the changes in relation to the time and the 
stochasticity of the activities present in the system, incorporating the whole country operations on a micro-regional level model, to its final international destinations.

In the search for tools which aid in better logistical systems planning, Discrete Event Simulation (DES) stands out as an effective alternative, seeing that through modelling, analysis and system design, the impacts of changing parameters can be viewed systemically, allowing complex analysis of the whole system, and not only the parts $[8,9]$.

However, the DES has a long tradition of application in the operational level, with applications for different types of manufacturing systems [10], or more recently, healthcare systems [11]. Logistic systems, in turn, are usually modelled through DES with an operational bias, to solve specific problems such as ports, loading and unloading systems and transport routes. This present work needs a method that provides a strategic analysis from the logistic system analysis, whose results enable long-term investment projections. The main works that relate simulation and strategic decisions use the simulation in dynamic systems, whose characteristics do not absorb the state change of variables each time but rather depending on the processed data, not designing operational stochastic systems for strategic decisions.

From this gap, this research used a DES project to simulate the Brazilian soybean logistics system using pre-defined regions and contemplating uni- and multimodal routes (both in operation and in the planning phase). The proposed method by [12] was used in this research, and has the following macro steps: conception, implementation and analysis. In the conception phase, was used IDEF-SIM technique [13]. The implementation was carried out in PROMODEL software and the analyses were performed in an experimental way, through the generation of current and projected comparative scenarios.

The results of the model enabled a strategic vision and make possible integrated decisionmaking regarding transportation investments. The variables are inter-related in a stochastic nature with internal model decisions, which are based on costs and route availability to influence the route selection. The DES is little used in simulation of systems whose decisions have strategic horizons. At this level of decision, works that apply in general to dynamic simulation are highlighted. In agribusiness, also are few the application of DES for large logistic systems.

Thus, the scientific contribution of this is to apply DES for strategic decision-making in the agribusiness supply chain, especially the soybean. Therefore, the scientific contribution of this work is to apply the DES for decisions making process in strategic level.

\section{BACKGROUND}

\subsection{The Brazilian agricultural logistics}

Inserted in the grain market, the soybean is also affected for Brazilian infrastructure problems. Soybeans represent Brazil's highest performing agricultural product [14]. Exportations related to Brazilian soybeans correspond to approximately $11 \%$ of the value of Brazilian exportations [4]. China is the largest importer, followed by member countries of the European Union. However, deficient logistics and underdeveloped infrastructure corrode this advantage [3]. Most soybean development has happened in the interior of the country, farthest from the exporting ports. The long distance creates logistical obstacles throughout the supply chain, resulting in a kind of 'bullwhip effect', which reaches the final destination.

In the last few years, many investigative studies have been developed to analyse the logistical challenges of Brazilian soybeans, with the use of many decision aiding tools, mainly optimization, location and simulation models for particular regions or production system. In large part of the works related to the soybean problematic, the studies are geared toward cost analysis and static mathematical models. 
A gap was identified between DES projects referring to simulation projects applied to large logistics systems, focused on strategic decisions. Among the most recent works: in [1] the authors proposed a smaller model that provided support for this work, focused on the logistics of a Brazilian state and its flow. The number of interrelated variables was considerably lower, as was the model's scope. In [5], a simulation project aimed at a specific company and its demand is proposed, with its focus on operational decision.

From the structuring and implementation of simulation of the project proposed in this work, will be discussed strategies of improvements in infrastructure and logistics for the flow of Brazilian soybean.

\section{SIMULATION PROJECT}

\subsection{Conception}

To develop this study, the technique IDEF-SIM [13] was applied in the conception phase, since it applies logical processes of interpretation, normally used in DES projects, with a strong diagrammatic representation.

\section{Problem situation - The logistical system}

The real system established for the model is the production of Brazilian soybeans destined for exportation. The country was divided into 19 producing regions, according to their production levels [15], with lesser levels of aggregation in micro-regions, according to the Fig. $1 \mathrm{a}$. The entity considered for analysis was denominated "soy" and each entity represents 1 ton of raw soybeans, which arrives at the micro-regions and runs through the system. The process of arrival of these entities is based on annual exportation by micro-region [16].

Brazil exported $55.74 \%$ of its soybean production in 2015 [4]. This percentage was also established in each of the 19 regions considered. For the DES model, this needs to be transformed into a discrete quantitative figure with a defined flow, which is denominated as the 'arrival process'. This process was defined as the value of 1 entity, equal to 1 ton of soybeans, with the quantitative amount for each proposed region arriving in integral proportional parts 8,640 times, for each hour of the annual simulation.

For the model, 10 Brazilian ports were considered for exportation, along with the Ilo Port (ILO), in Peru, for certain scenarios. In relation to the final destinations, Shanghai (SHA), China and Hamburg (HAM), Germany, were considered. For each exporting port, a percentage was determined.

Starting at each origin point, there are a total of 21 possible alternatives for transportation routes according to the constructed scenarios. Ten alternative roadways and 11 multi-modal alternatives were defined with the main axes for grain transportation, using both existing and projected routes. As such, 399 roadways were established for unimodal (only roadways) and multi-modal routes. The road distances were established using mapping software and available routes. The model's routing is shown in Table I.

In terms of capacity, for the roadways, a bulk carrier semi-trailer was defined (capacity of 37 tons). For maritime routes, the type of vessel considered was the Handymax ship (capacity of 55,000 tons).

Fig. 1 a shows the territorial division for the development of the model, while Fig. $1 \mathrm{~b}$ presents the exporting ports and the multi-modal terminals considered. The roadways, given their quantity of origin points, were not represented graphically (11 routes for 19 origins, adding the 11 which lead to the terminals).

Speed values were collected and allocated for the Brazilian roadways, waterways and railways. For the maritime transportation, which was considered to have a maximum speed standard of 20 knots. 
Table I: Routes defined for the model.

\begin{tabular}{|c|c|c|c|c|c|c|}
\hline Route & Type & Mode & Origin - Destination & $\begin{array}{c}\text { Distance } \\
(\mathrm{km})\end{array}$ & $\begin{array}{c}\text { Transportation } \\
\text { modes }\end{array}$ & $\begin{array}{l}\text { Current } \\
\text { situation }\end{array}$ \\
\hline \multirow{2}{*}{1} & \multirow{2}{*}{ M } & RO & Origin - Porto Velho Terminal & Varied & Truck & \multirow{2}{*}{ Op } \\
\hline & & $\mathrm{W}$ & Porto Velho Terminal - ITA & 1,100 & Barges $40000 \mathrm{MT}$ & \\
\hline 2 & $\mathrm{U}$ & RO & Origin - STM & Varied & Truck & Op \\
\hline 3 & $\mathrm{U}$ & RO & Origin - VDC & Varied & Truck & Op \\
\hline 4 & $\mathrm{U}$ & RO & Origin - ITQ & Varied & Truck & $\mathrm{Op}$ \\
\hline 5 & $\mathrm{U}$ & $\mathrm{RO}$ & Origin - SSA & Varied & Truck & $\mathrm{Op}$ \\
\hline 6 & $\mathrm{U}$ & $\mathrm{RO}$ & Origin - VIX & Varied & Truck & $\mathrm{Op}$ \\
\hline 7 & $\mathrm{U}$ & RO & Origin $-\mathrm{SSZ}$ & Varied & Truck & $\mathrm{Op}$ \\
\hline 8 & $\mathrm{U}$ & RO & Origin $-\mathrm{PRG}$ & Varied & Truck & $\mathrm{Op}$ \\
\hline 9 & $\mathrm{U}$ & $\mathrm{RO}$ & Origin - SFS & Varied & Truck & Op \\
\hline 10 & $\mathrm{U}$ & RO & Origin - RGD & Varied & Truck & Op \\
\hline 11 & $\mathrm{U}$ & RO & Origin - ILO & Varied & Truck & $\mathrm{Op}$ \\
\hline \multirow{2}{*}{12} & \multirow{2}{*}{ M } & RO & Origin - Conceição do Araguaia Terminal & Varied & Truck & \multirow{2}{*}{ Proj } \\
\hline & & $\mathrm{W}$ & Conceição do Araguaia Terminal - VDC & 1,083 & Barges 8,000 MT & \\
\hline \multirow{2}{*}{13} & \multirow{2}{*}{ M } & $\mathrm{RO}$ & Origin - Itaituba Terminal & Varied & Truck & \multirow{2}{*}{ Op } \\
\hline & & $\mathrm{W}$ & Itaituba Terminal - VDC & 850 & Barges 40,000 MT & \\
\hline \multirow{2}{*}{14} & \multirow{2}{*}{$\mathrm{M}$} & RO & Origin - Palmas Terminal & Varied & Truck & \multirow{2}{*}{ Op } \\
\hline & & RA & Palmas Terminal - ITQ & 968 & Train 6,200 MT & \\
\hline \multirow{2}{*}{15} & \multirow{2}{*}{ M } & RO & Origin - Pirapora Terminal & Varied & Truck & \multirow{2}{*}{ Op } \\
\hline & & RA & Pirapora Terminal - VIX & 1,000 & Train 6,200 MT & \\
\hline \multirow{3}{*}{16} & \multirow{3}{*}{ M } & RO & Origin - São Simão Terminal & Varied & Truck & \multirow{3}{*}{ Op } \\
\hline & & $\mathrm{W}$ & São Simão Terminal - Anhembi Terminal & 760 & Barges 6,000 MT & \\
\hline & & RO & Anhembi Terminal - SSZ & 276 & Truck & \\
\hline \multirow{2}{*}{17} & \multirow{2}{*}{ M } & RO & Origin - Rondonópolis Terminal & Varied & Truck & \multirow{2}{*}{ Op } \\
\hline & & RA & Rondonópolis Terminal - SSZ & 1,700 & Train $6200 \mathrm{MT}$ & \\
\hline \multirow{2}{*}{18} & \multirow{2}{*}{ M } & $\mathrm{RO}$ & Origin - Maringá Terminal & Varied & Truck & \multirow{2}{*}{ Proj } \\
\hline & & RA & Maringá Terminal - PRG & 545 & Train 6,200 MT & \\
\hline \multirow{2}{*}{19} & \multirow{2}{*}{ M } & $\mathrm{RO}$ & Origin - Porto União Terminal & Varied & Truck & \multirow{2}{*}{ Proj } \\
\hline & & RA & Porto União Terminal - SFS & 437 & Train 6,200 MT & \\
\hline \multirow{2}{*}{20} & \multirow{2}{*}{ M } & RO & Origin - Cruz Alta Terminal & Varied & Truck & \\
\hline & & RA & Cruz Alta Terminal - RGD & 507 & Train 6,200 MT & Proj \\
\hline 21 & $M$ & RO & Origin - Campo Grande Terminal & Varied & Truck & \\
\hline 21 & MI & RA & Campo Grande Terminal - ILO & 2,384 & Train 6,200 MT & Proj \\
\hline
\end{tabular}

M - Multimodal; U - Unimodal; RO - Roadway; RA - Railway; W - Waterway; Op - In Operation; Proj - Projected

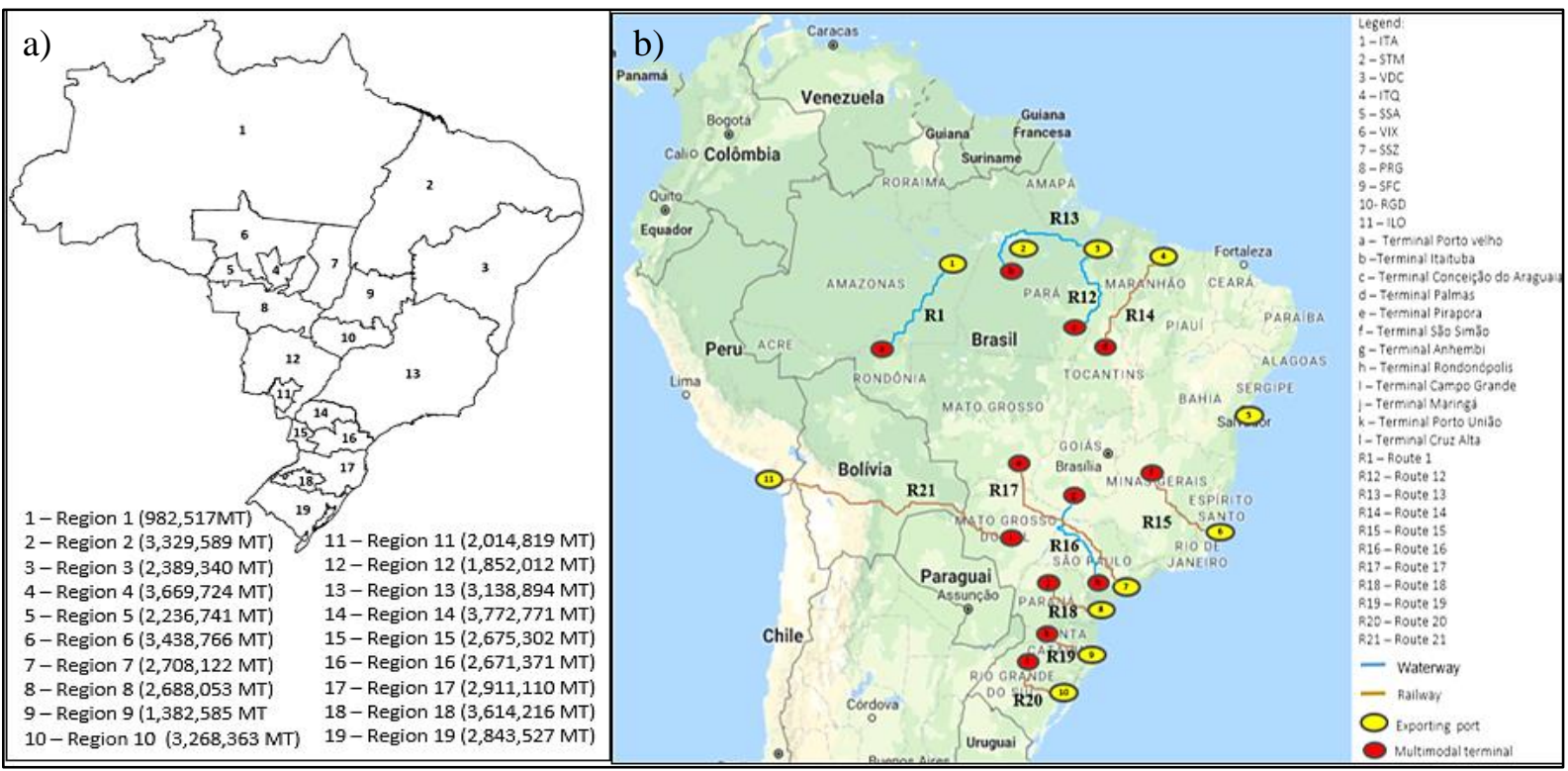

Figure 1: a) Representation of the regions determined as origins; b) Representation of the exporting ports and multi-modal terminals. 
The stochastic nature of the model is worth highlighting, due to the use of a triangular distribution. In order to verify the acceptability of the triangular distribution, the tool Stat::Fit was used within the software package PROMODEL. In all of the data sets, a triangular distribution was considered acceptable. Storage data from the static capacity of export ports and multimodal terminals were consolidated in Table II.

Table II: Capacity of the shipment locations (Exporting ports and multimodal terminals) [16].

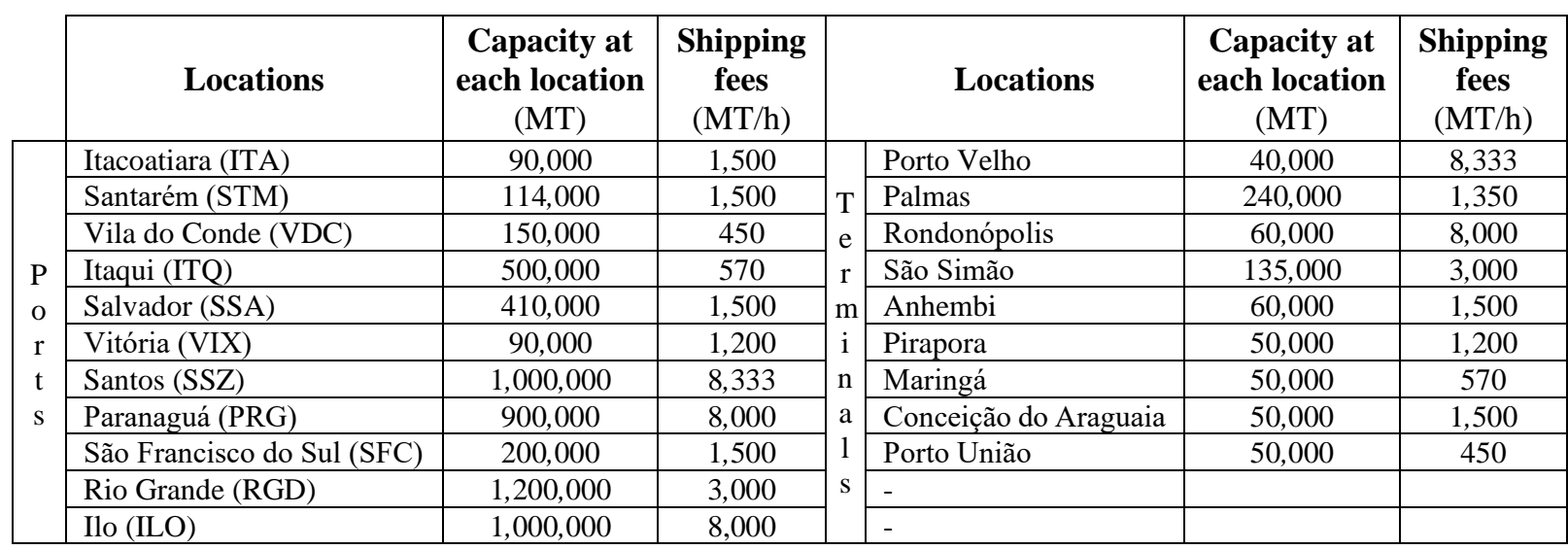

\section{Costs}

The costs considered for the model are attributed to each route per each ton transported. These costs, aside from being utilized to compare scenarios, are logical components used for the model's decision-making processes, given that this is the first decision criterion for the choice of the route. These costs per modal are presented in Table III. In the model, the costs presented the following composition, for each $x_{i j}$ (with $x_{i j}$ being each chosen route between $i$ and $j$ ). The logistics costs between the producing origin $i$ to the exporting port $j\left(c_{i j}\right)$ are expressed by Eq. (1), with restriction of Eq. (2).

$$
c_{i j}=c_{r o}+c_{r a}+c_{w}+c_{p}+c_{t}+c_{m}
$$

$c_{r o}-$ cost of road, in USD/ton,

$c_{r a}-$ cost of rail, in USD/ton, if there is,

$c_{w}-$ cost of waterway, in USD/ton km, if there is,

$c_{p}$ - cost of port handling,

$c_{m}-$ cost of maritime transport, in USD/ton; and

$c_{t}-$ cost of transhipment, in USD/ton, in the case of using more than one mode of transport, with:

$$
t \geq 0
$$

\begin{tabular}{|c|c|c|c|}
\hline Mode & Value (USD/ton km) & Mode & Value \\
\hline Roadway & 0.0467 & Maritime & $0.003 \mathrm{USD} /$ ton $\mathrm{km}$ \\
\hline Railway & $\begin{array}{lr}0 \text { to } 400 \mathrm{~km}-0.0251 & 401 \text { to } 800 \mathrm{~km}-0.0226 \\
801 \text { to } 1600 \mathrm{~km}-0.0175 & \text { Above } 1601 \mathrm{~km}-0.0121 \\
\end{array}$ & Transhipment & 0.6349 USD/ton \\
\hline Waterway & 0.025 & & \\
\hline
\end{tabular}

Table III: Costs for logistics operations included in the model $[3,4] . \mathrm{R} \$ 3,15=1 \mathrm{USD}$.

\section{Application of IDEF-SIM technique}

Fig. 2 shows the studied system diagrammed in the IDEF-SIM technique. 


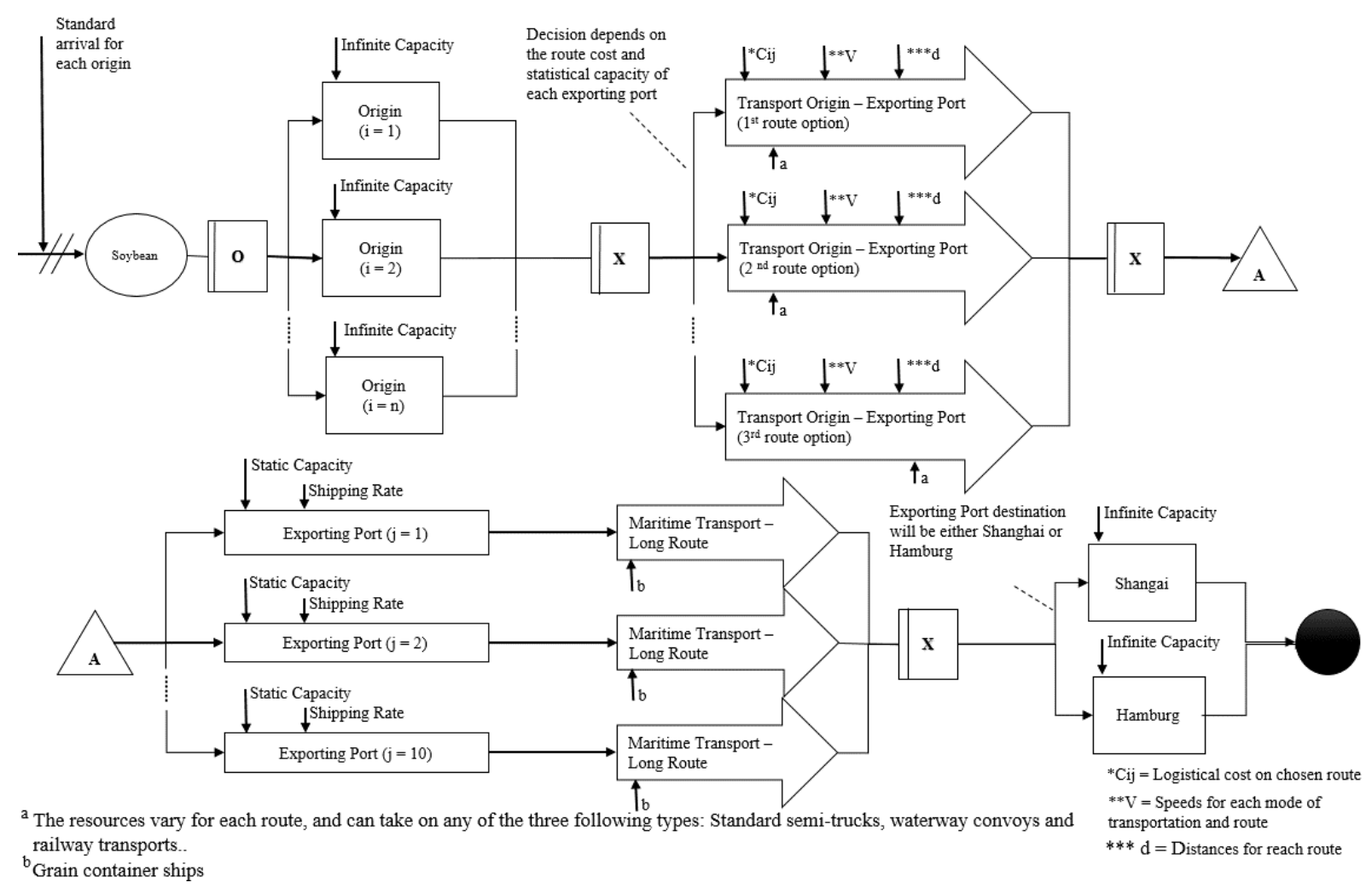

Figure 2: Representation of the applied model using the IDEF-SIM technique.

As shown in the Fig. 2, the costs for each route are initially informed from an external source and ordered during the initialization of the computational model to classify the chosen route. The statistical capacity is made up by the availability of storage and receiving capacity at port $j$. These two variables are necessary to choose the route. The speed $(V)$ is random in nature and is obtained through the routing software for all routes to the exporting ports and associated to a probability distribution. The distances $(d)$ were defined based on online routing software and follow a rule to always choose the shortest route from origin to destination. The shipping rate is the speed in loading the Grain Ships at port $j$, which directly interferes with the statistical capacity of each port and, in turn, the choice of the best route. Trucks are always available on roadway stretches, and ships are always available at ports, being used according to the loading rate.

\subsection{Implementation of the computational model}

The computational model was implemented in the simulation software PROMODEL. Fig. 3 presents the graphic layout of the computational model.

\section{Performance measurements for simulation.}

The model output parameters are the performance measurements, which underlie the proposed scenarios as well as the adjustments and suggestions to the model (Table IV). All scenarios are simulated for one year (8,640 hours), based on the annual exportation demand, for a strategic evaluations and planning of the studied system.

Table IV: Measurements for system performance.

\begin{tabular}{|l|c|}
\hline \multicolumn{1}{|c|}{ Measurements for system performance } & Unit \\
\hline Soybeans shipped in tons & MT \\
\hline Quantity of soybeans bound for exporting port & MT - Percentage \\
\hline Quantity of soybeans bound for internal routes & MT - Percentage \\
\hline Quantity of soybeans bound, per port, to each importing port & MT - Percentage \\
\hline
\end{tabular}




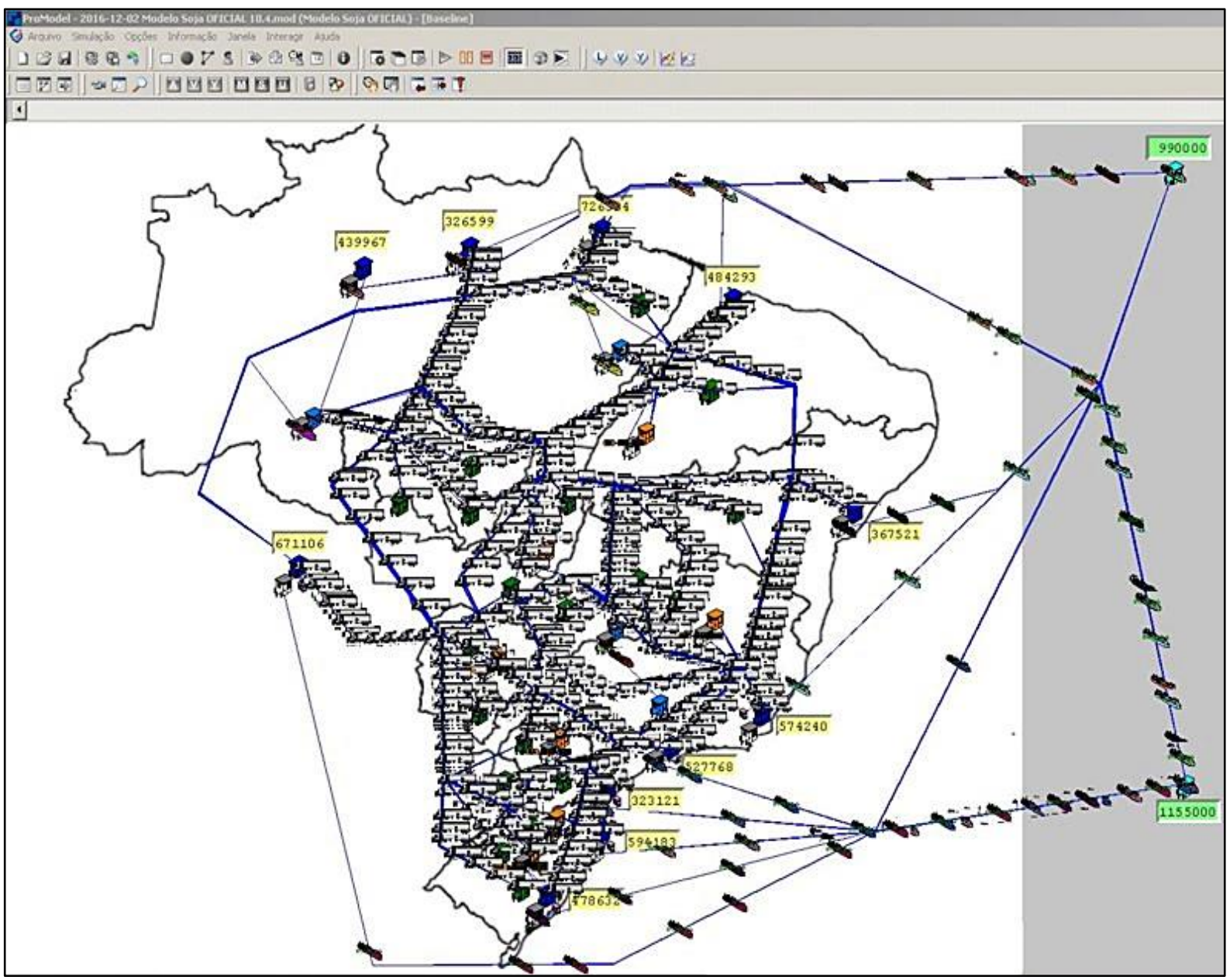

Figure 3: Graphic layout of the computational model.

\section{Number of replications}

The scenario $\mathrm{C} 1 \mathrm{a}$ (presented in section 3.3) was used to calculate the number of replications to be simulated. That characteristic enables it to be used for Confidence Interval Methods (with Specified Precision - for non-terminal system) $[17,18]$. The number of replications established was 7.

\section{Validation of computational model}

To conduct this validation, the variable "ExportShanghai" was used to represent the quantity delivered to the destination. The validation for either destination serves for both in percentage terms. Of the total soybeans exported from these two destinations $(54,322,651)$ in $2015,87.8 \%$ was bound to China and $12.2 \%$ to Europe.

This value was used for validation with the simulated results, using the one-sample $t$ test [19]. It was chosen due to the fact the real quantity of soybeans exported is a deterministic value in a simulated period. This value was compared to the results obtained in the replications of the simulations. The data for the one-sample $t$ test are found in Table V.

Table V: Results from one-sample $t$ test for the variable "ExportShanghai".

\begin{tabular}{|c|c|c|c|c|c|c|}
\hline Variable & $\begin{array}{c}\text { Expected } \\
\text { value }\end{array}$ & $\begin{array}{c}\text { Number of } \\
\text { replications }\end{array}$ & Mean & $\begin{array}{c}\text { Standard } \\
\text { deviation }\end{array}$ & $\begin{array}{c}\mathbf{9 5} \% \text { confidence } \\
\text { interval }\end{array}$ & $\boldsymbol{P}$-value \\
\hline ExportShanghai & $47,470,266$ & 7 & $47,330,000$ & 500,470 & $(47,146,122 ; 47,519,878)$ & 0.144 \\
\hline
\end{tabular}

Starting with Table V, it can be verified that the results of model are valid in relation to the real system, which positively confirms the validation process. In spite of the statistical tests 
carried out for verification and validation, it is worth highlighting that the validation process for DES models cannot always be carried out using the traditional methods seen in the literature due to the grand scale of the studied case. Scenario C1a is not a simple reproduction of the real system, seeing that the initialization decision logic interferes with its behaviour in comparison with the real system, given that this scenario is considered an experiment. This logic validates the model in reference to decision execution, while other variables may differ in relation to the real system.

\subsection{Analysis}

To consolidate and analyse this research study, 13 scenarios were described and applied using three variations of projections, which add up to a total of 39 scenarios. These ones were considered the most important for analysis and discussion in respect to Brazilian soybean transportation, with the main existing transportation vectors and those still under development or conception used as logistical alternatives.

\section{Scenarios Construction}

The data refer to the soybean exportation for the year 2015. The projections realized are based on these data. Scenarios 1 to 11 were constructed without annual limits for port capacity, with limitations for rates and operational capacities (Fig. 4). New scenario set were elaborated in 12 and 13 in order to assess the behaviour of the simulated model under a scenario of port restriction in SSZ and PRG, which already has real soybean exportation capacity limitations.

The set of scenarios 12 (C12a, C12b and C12c) follow the construction of Scenario 1 and its projections. Scenario 13 reproduces what is seen in Scenario 11 and its projections. The choice of these scenarios (1 to 11) for the construction of the additional scenarios 12 and 13 are due to the fact that Scenario 1 represents the closest approximation to the real operational system, and because Scenario 11 is the most complete one in terms of projections considered, associated with the optimal results in terms of costs. Fig. 4 summarizes the construction of the 39 scenarios presented in reference to the constructed routes.

Scenario 1

Figure 4: Schematic representation of the scenarios' construction. 
At the end of the simulation of the scenarios, the average values from the replications were multiplied by the costs presented in Table III, in order to arrive at the costs per scenario, as presented in Table VI.

Table VI: Costs per scenario.

\begin{tabular}{|c|c|c|c|c|c|c|c|}
\hline Scenario & $\begin{array}{c}\text { Total cost } \\
\text { (USD) }\end{array}$ & $\begin{array}{c}\text { Cost per ton } \\
\text { (USD/MT) }\end{array}$ & $\begin{array}{c}\text { Reduction } \\
\text { (\% scenario 1) }\end{array}$ & Scenario & $\begin{array}{c}\text { Total cost } \\
\text { (USD) }\end{array}$ & $\begin{array}{c}\text { Cost per ton } \\
\text { (USD/MT) }\end{array}$ & $\begin{array}{c}\text { Reduction } \\
(\% \text { scenario 1) }\end{array}$ \\
\hline C1a & $2,432,829,610$ & 44.78 & - & C7c & $3,345,747,843$ & 42.88 & $4.5 \%$ \\
\hline C1b & $2,683,903,262$ & 44.85 & - & C8a & $2,431,061,226$ & 44.75 & $0.1 \%$ \\
\hline C1c & $3,502,467,130$ & 44.89 & - & C8b & $2,682,791,377$ & 44.83 & $0.0 \%$ \\
\hline C2a & $2,363,065,980$ & 43.50 & $2.9 \%$ & C8c & $3,501,016,919$ & 44.87 & $0.0 \%$ \\
\hline C2b & $2,615,087,201$ & 43.70 & $2.6 \%$ & C9a & $2,427,726,177$ & 44.69 & $0.2 \%$ \\
\hline C2c & $3,404,972,276$ & 43.64 & $2.8 \%$ & C9b & $2,678,276,682$ & 44.76 & $0.2 \%$ \\
\hline C3a & $2,377,862,134$ & 43.77 & $2.3 \%$ & $\mathbf{C 9 c}$ & $3,501,765,846$ & 44.88 & $0.0 \%$ \\
\hline C3b & $2,630,574,624$ & 43.96 & $2.0 \%$ & $\mathbf{C 1 0 a}$ & $2,303,140,188$ & 42.39 & $5.3 \%$ \\
\hline C3c & $3,451,291,573$ & 44.24 & $1.5 \%$ & $\mathbf{C 1 0 b}$ & $2,522,013,329$ & 42.15 & $6.0 \%$ \\
\hline C4a & $2,433,842,011$ & 44.80 & $0.0 \%$ & $\mathbf{C 1 0 c}$ & $3,354,133,160$ & 42.99 & $4.2 \%$ \\
\hline C4b & $2,683,330,378$ & 44.84 & $0.0 \%$ & $\mathbf{C 1 1 a}$ & $2,241,385,097$ & 41.26 & $7.9 \%$ \\
\hline C4c & $3,492,114,863$ & 44.76 & $0.3 \%$ & $\mathbf{C 1 1 b}$ & $2,487,700,683$ & 41.57 & $7.3 \%$ \\
\hline C5a & $2,394,309,378$ & 44.07 & $1.6 \%$ & $\mathbf{C 1 1 c}$ & $3,295,175,338$ & 42.23 & $5.9 \%$ \\
\hline C5b & $2,641,355,735$ & 44.14 & $1.6 \%$ & $\mathbf{C 1 2 a}$ & $2,422,336,665$ & 44.59 & $0.4 \%$ \\
\hline C5c & $3,447,137,763$ & 44.18 & $1.6 \%$ & $\mathbf{C 1 2 b}$ & $2,684,403,345$ & 44.86 & $0.0 \%$ \\
\hline C6a & $2,317,883,116$ & 42.66 & $4.7 \%$ & $\mathbf{C 1 2 c}$ & $3,503,770,254$ & 44.91 & $0.0 \%$ \\
\hline C6b & $2,527,639,909$ & 42.24 & $5.8 \%$ & $\mathbf{C 1 3 a}$ & $2,243,921,572$ & 41.30 & $7.8 \%$ \\
\hline C6c & $3,429,030,699$ & 43.95 & $2.1 \%$ & $\mathbf{C 1 3 b}$ & $2,483,893,382$ & 41.51 & $7.5 \%$ \\
\hline C7a & $2,248,119,485$ & 41.38 & $7.6 \%$ & $\mathbf{C 1 3 c}$ & $3,294,651,581$ & 42.23 & $5.9 \%$ \\
\hline C7b & $2,496,740,015$ & 41.72 & $7.0 \%$ & & & & \\
\hline & & & & & & \\
\hline
\end{tabular}

In order to carry out a cost comparison, Table VII shows selected values available in [4], which are for soybean transportation (the study considers roadway transport as internal transportation from the soybean origin points to the exporting ports) from regions in Brazil to SHA and HAM.

Table VII: Actual costs of soybean transportation, in 2017 [4].

\begin{tabular}{|l|c|l|c|}
\hline $\begin{array}{c}\text { Origin - Exporting Port - } \\
\text { Final destination }\end{array}$ & $\begin{array}{c}\text { Cost of transportation } \\
\text { (USD/MT) }\end{array}$ & $\begin{array}{c}\text { Origin - Exporting Port - } \\
\text { Final destination }\end{array}$ & $\begin{array}{c}\text { Cost of transportation } \\
\text { (USD/MT) }\end{array}$ \\
\hline Mato Grosso State - STM - SHA & 71.14 & Mato Grosso State - SSZ - HAM & 93.62 \\
\hline Mato Grosso State - SSZ - SHA & 92.13 & Paraná State - PRG - HAM & 39.68 \\
\hline Paraná State - PRG - SHA & 39.43 & Mato Grosso State - STM - HAM & 64.60 \\
\hline Piauí State - ITQ - SHA & 53.78 & Piauí State - ITQ - HAM & 45.97 \\
\hline
\end{tabular}

From the results in Table VII, it can be seen that only rearranging Brazilian soybean allocation would already considerably reduce global transportation costs. The Mid-West region makes up $44 \%$ of the country's soybean production. The average cost found in the simulations would reduce total logistical costs by half in this region. The MATOPIBA region (11\% of all Brazilian soybeans, represented by the state of Piauí), in the proposal of Scenario 1, its value would be around USD 10.00/MT below what is currently seen to SHA and around USD 1.00/MT below the price seen to HAM. Only soybeans originating from the Southern region, has highest values than the average found in Scenario 1 (around $12 \%$ ). The real average cost found was approximately USD 54/MT transported, from origin to final destination. Based on this cost per ton, the values found in Scenario 1 would present an approximate reduction of $17 \%$, this being achieved by only rearranging the decision-making process for allocation and the use of real routes. The four main scenarios considered (1, 2, 3 and 11) are presented in Fig. 5. 

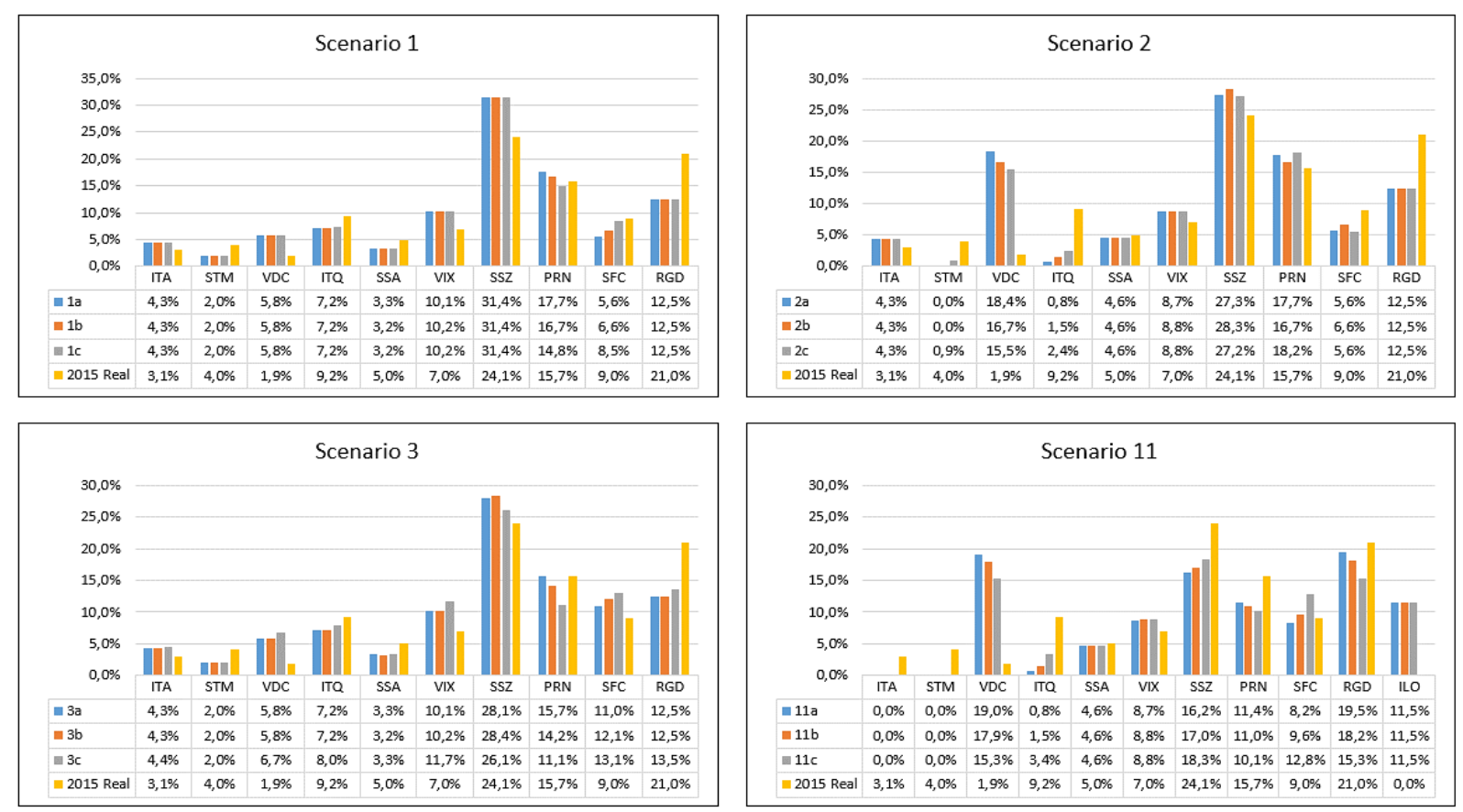

Figure 5: Percentage results of the scenarios 1,2, 3 and 11.

Regarding the scenarios and their results, the following observations can be made: in Scenario 2, significant cost reductions are presented - in between $2.6 \%$ to $2.9 \%$, presenting the insertion of ATW as the alternative for Brazilian soybean outflow. The cost of implementing the waterway in the studied portion is around USD 762 million [20]. Scenario 3, in comparison with Scenario 1 and its projections, present a reduction of $2.3 \%$ in costs for $2015 ; 2.0 \%$ in 2018; and $1.5 \%$ in the 2026 projection. This scenario stands out by adding a railway, which extends $545 \mathrm{~km}$ (RA1). The cost of implementing a railway is around USD 635 thousand per kilometre [21]. Scenario 6 integrates and adds RA1, RA2 and RA3 to the routes in Scenario 1. The construction of the three railways in question would have a cost of approximately USD 950 million [20]. However, it is worth noting that the railway to São Francisco do Sul is not competitive in its operation. If this railway were excluded, the cost of the other two would be USD 670 million. Scenarios 8 and 9 add the roadways and railways to the ILO did not exhibit a competitive nature in relation to scenario 1. The results from Scenarios 12 and 13 were similar to the results of 1 and 11 . ATW, RA1 and RA3 are the most effective alternatives to reduce costs and improve soybean logistics.

\section{CONCLUSIONS}

This study proposed the construction of a DES project to analyse the Brazilian soybean exportation. In doing so, the study contributes to scientific knowledge in its use of DES as an analysis tool for strategic decision-making analysis and use of DES in a large-scale logistical system with the dimensions of the studied system and large number of inter-related variables. In [1], a prototype by the same authors was applied to only one Brazilian state, while this study covers the whole country and its soy exports, increasing not only the number of variables and their interrelationships, but also the level and horizon of decision proposed in the model.

Given the system's grand scale, the model proved to be effective by generating coherent solutions, which enabled the representation of different situations in different scenarios. The scenarios permitted the analysis of the logistical system, aiding in the discussion of soybean allocation from its origin to the routes and exporting ports considered before reaching their final destinations. 
Among the results of the scenarios, the greatest feasibility was seen in Scenarios 1, 2, 3, 4 and 11 , in terms of costs. The simulations indicated the necessity and viability of investment in the ATW waterway and in the RA1 and RA3 railways. The implementation of these routes would minimize bottleneck in the country's regions, better distributing the flow of soy to the final destinations. The investments of these alternatives are compensated on a timeline of fewer than 10 years.

After comparing simulated and real costs, it was verified that integrated decision-making between organizations would reduce logistical costs by $17 \%$, only through rational allocation and utilization of existing routes. Thus, in Brazil, is suggested the integration between organizations and the public and private sectors for a greater rationalization of resources and international competitiveness. For future studies, potential research areas include the investigation of factors related to climate, soil and variables which reflect socio-environmental projections.

This study was carried out for soybean logistics. However, the logistics alternatives presented in this paper will, in almost all cases, transport other cargo simultaneously, which could benefit from the same alternatives discussed herein. Integrated and individual studies for other cargo related to freight and return costs become attractive from a strategic context and can continue to increase Brazilian agribusiness on a global scale.

\section{ACKNOWLEDGEMENT}

The authors thank CAPES, CNPQ and FAPEMIG for their support.

\section{REFERENCES}

[1] Dos Santos Lopes, H.; da Silva Lima, R.; Leal, F.; de Carvalho Nelson, A. (2017). Scenario analysis of Brazilian soybean exports via discrete event simulation applied to soybean transportation: the case of Mato Grosso State, Research in Transportation Business \& Management, Vol. 25, 66-75, doi:10.1016/j.rtbm.2017.09.002

[2] Friend, J. D.; da Silva Lima, R. (2011). Impact of transportation policies on the competitiveness of Brazilian and U.S. Soybeans: from field to port, Transportation Research Record: Journal of the Transportation Research Board, Vol. 2238, No. 1, 61-67, doi:10.3141/2238-08

[3] Dos Santos Lopes, H.; da Silva Lima, R.; Costa Ferreira, R. (2016). A cost optimization model of transportation route to export the Brazilian soybean, Costs and Agribusiness, Vol. 12, No. 4, 90109

[4] Salin, D. L. (2017). Soybean Transportation Guide: Brazil 2016, United States Department of Agricultural, Agricultural Marketing Service, Washington, doi:10.9752/TS048.05-2017

[5] Fioroni, M. M.; Franceza, L. A. G.; de Santana, I. R.; Lelis, P. E. P.; da Silva, C. B.; Telles, G. D.; Quintáns, J. A. S.; Maeda, F. K.; Varani, R. (2015). From farm to port: simulation of the grain logistics in Brazil, Proceedings of 2015 Winter Simulation Conference, 1936-1947, doi:10.1109/WSC.2015.7408310

[6] De Oliveira, A. L. R.; Alvim, A. M. (2017). The supply chain of Brazilian maize and soybeans: the effects of segregation on logistics and competitiveness, International Food and Agribusiness Management Review, Vol. 20. No. 1, 45-61, doi:10.22434/IFAMR2016.0084

[7] Fliehr, O.; Zimmer, Y.; Smith, L. H. (2019). Impacts of transportation and logistics on Brazilian soybean prices and exports, Transportation Journal, Vol. 58, No. 1, 65-77, doi:10.5325/ transportationj.58.1.0065

[8] Sargent, R. G. (2013). An introduction to verification and validation of simulation models, Proceedings of 2013 Winter Simulation Conference, 321-327, doi:10.1109/WSC.2013.6721430

[9] Vieira, A. A. C.; Dias, L. M. S.; Santos, M. Y.; Pereira, G. A. B.; Oliveira, J. A. (2018). A setting an Industry 4.0 research and development agenda for simulation - a literature review, International Journal of Simulation Modelling, Vol. 17, No. 3, 377-390, doi:10.2507/IJSIMM17(3)429 
[10] Negahban, A.; Smith, J. S. (2014). Simulation for manufacturing system design and operation: literature review and analysis, Journal of Manufacturing Systems, Vol. 33, No. 2, 241-261, doi:10.1016/j.jmsy.2013.12.007

[11] Fragapane, G. I.; Zhang, C.; Sgarbossa, F.; Strandhagen, J. O. (2019). An agent-based simulation approach to model hospital logistics, International Journal of Simulation Modelling, Vol. 18, No. 4, 654-665, doi:10.2507/IJSIMM18(4)497

[12] Montevechi, J. A. B.; de Pinho, A. F.; Leal, F.; Marins, F. A. S. (2007). Application of design of experiments on the simulation of a process in an automotive industry, Proceedings of the 2007 Winter Simulation Conference, 1601-1609, doi:10.1109/WSC.2007.4419779

[13] De Silva, C. E. S.; Gomes Salgado, E.; Pereira Mello, C. H.; de Silva Oliveira, E.; Leal, F. (2014). Integration of computer simulation in design for manufacturing and assembly, International Journal of Production Research, Vol. 52, No. 10, 2851-2866, doi:10.1080/00207543.2013.853887

[14] Cattelan, A. J.; Dall'agnol, A. (2018). The rapid soybean growth in Brazil, Oilseeds \& Fats Crops and Lipids, Vol. 25, No. 1, Paper D102, 12 pages, doi:10.1051/ocl/2017058

[15] Brazilian Institute of Geography and Statistics. Sistema IBGE de Recuperação Automática SIDRA, from https://sidra.ibge.gov.br/home/pnadcm, accessed on 14-02-2019

[16] Ministry of Industry, Foreign Trade and Services (Secretariat of Foreign Trade - SECEX). System of Analysis of Foreign Trade Information, from http://aliceweb.mdic.gov.br, accessed on 09-052017

[17] Banks, J. (1998). Handbook of Simulation: Principles, Methodology, Advances, Applications, and Practice, $1^{\text {st }}$ edition, John Wiley \& Sons, New York

[18] Palma Lima, J.; Dias Lobato, K. C.; Leal, F.; da Silva Lima, R. (2015). Urban solid waste management by process mapping and simulation, Pesquisa Operacional, Vol. 35, No. 1, 143-163, doi:10.1590/0101-7438.2015.035.01.0143

[19] Montgomery, D. C.; Runger, G. C. (2011). Applied Statistics and Probability for Engineers, $5^{\text {th }}$ edition, John Wiley \& Sons, Hoboken

[20] National Waterway Transportation Agency (ANTAQ), from http://www.antaq.gov.br/portal/pdf/ palestras/mar0722palestraenephadalberto.pdf, accessed on 15-06-2019

[21] FCASA. Projetos Noroeste de Minas (in Portuguese), from http://www.fcasa.com.br/ projetos/noroeste-de-minas/, accessed on 04-06-2019 